\title{
REPRODUCTIVE IMPAIRMENT IN ZEBRA FINCHES (TAENIOPYGIA GUTTATA)
}

\author{
Almira L. Hoogesteijn, ${ }^{*} \dagger$ Timothy J. DeVoogd, \\ GeOrge V. Kollias $\dagger$ \\ $\dagger$ Division of Wildlife Health, New York State College of Veterinary Medicine, Cornell University, Ithaca, New York 14853, USA \\ $\ddagger$ Department of Psychology and Neurobiology, Cornell University, Ithaca, New York 14853, USA \\ $\S$ Lab Animal Research Center, The Rockefeller University, 1230 York Avenue, New York, New York 10021, USA \\ |Department of Public Health, State University of New York at Albany, 1 University Place, Room B 339, Rensselaer, New York 12144, USA
}

(Received 14 November 2003; Accepted 29 June 2004)

\begin{abstract}
The effects of polychlorinated biphenyls (PCBs) as compounds that may disrupt endocrine activity and, consequently, alter reproductive performance were investigated in altricial zebra finches (Taeniopygia guttata). The breeding performance and breeding cycle of zebra finches differed significantly between nonexposed birds and those experimentally pulse-exposed to Aroclor 1248, a PCB compound (40 $\mu \mathrm{g} / \mathrm{bird})$. Aroclor-exposed birds showed significantly increased numbers of clutches laid, nests constructed per pair, incubation time per pair, and percentage of hatchling mortality compared to controls. Not all reproductive parameters were affected. Those traditionally regarded as indicators of reproductive capacity (number of eggs laid per clutch, number of eggs laid per pair, hatchlings per clutch, and fledglings per clutch) did not differ statistically between exposed and control birds. Findings support the hypothesis that very low PCB doses may be associated with endocrine disruption. It is suggested that evaluation of reproductive parameters related to parental care is more adequate to assess endocrine disruption than is evaluation of reproductive success parameters. Given its short breeding cycle, altricial breeding behavior, and other advantages not possessed by precocial birds, we propose using the zebra finch for evaluations of chemicals with endocrine-disruptive activity.
\end{abstract}

Keywords-Polychlorinated biphenyls Zebra finches Endocrine disruption Fertility Altricial birds

\section{INTRODUCTION}

Polychlorinated biphenyls (PCBs) have been identified as some of the most persistent industrial contaminants present in almost every trophic level of the ecosystem [1]. Up to one third of all PCBs produced in the United States have been reported to have entered the environment $\left(\sim 630 \times 10^{6} \mathrm{~kg}[2]\right)$. Seventy percent of the PCBs produced in the world are still in use or in stock and, therefore, could enter the environment in the future $[3,4]$. Polychlorinated biphenyls are known to exert disruptive effects on endocrine-regulated processes, such as reproduction [5]. A PCB congener is a simple, unique, welldefined chemical compound characterized by the number and position of chlorine substitutes in a biphenyl molecule. Coplanar PCB $77\left(3,3^{\prime}, 4,4^{\prime}\right.$-tetrachlorobiphenyl), PCB 126 (3, 3',4,4',5-pentachlorobiphenyl), and PCB 169 (3,3', 4, 4', 5, 5' hexachlorobiphenyl) have been defined as the most toxic PCB congeners. They have substitutions in both para ( 4 and $\left.4^{\prime}\right)$ and at least 2 or more meta $\left(3,3^{\prime}, 5\right.$, and $\left.5^{\prime}\right)$ positions. The actions of coplanar PCBs are similar to those reported for 2,3,7,8tetrachlorodibenzo- $p$-dioxin and may act by the same receptormediated mechanism proposed for halogenated aryl hydrocarbons [1]. A second group of PCBs, namely all the ortho analogs of the coplanar PCBs, elicits a comparable spectrum of responses but has been defined as less toxic than coplanar analogs. Data for the ortho-rich congeners are very scant and their structure-related activity is not known at this time [6]. Ortho substitutes have been described to increase synthesis of

* To whom correspondence may be addressed (ahoogesteyn@wcs.org).

Treatment and care of experimental birds (zebra finches [Taeniopygia guttata]) were conducted in accordance with regulations set forth by Cornell's Institutional Animal Care and Use Committee (protocol 99-100). protooncogenes, enzymes from the cytochrome P450 complex (such as CYP2A, CYP2B, and CYP3A), and steroid catabolism, and also to induce bile duct hyperplasia, hepatomegaly, neoplasia, gastroenteritis, anemia, neutrophil activation, embryo death, estrogen activity, dopamine decrease, calcium channel activation, insulin release, and oxidative stress [6]. Commercially, PCBs have been prepared by the chlorination of a biphenyl molecule. For example, Aroclor 1248 (AccuStandard, New Haven, CT, USA) contains $48 \%$ chlorine (by weight), and can possess up to 132 individual congeners [7]. Studies conducted during the late 1970s and 1980s on bird populations heavily contaminated with organochlorine pollutants reported reproductive behavioral abnormalities. These studies postulated that $\mathrm{PCB}$ s were associated with reproductive failure. They also suggested that increased exposure to organochlorines had important reproductive effects that influenced recruitment of the next generation and, therefore, threatened the survival of some species [8-11]. The traditional indicators of avian reproductive ability are egg production, clutch size, hatchability, eggshell quality, and nestling mortality [12]. However, differences in these parameters can be less obvious if exposure levels are low. Zebra finches (Taeniopygia guttata) provide an opportunity to assess the effect of PCBs under controlled laboratory conditions. Zebra finches are small song birds of Australian origin that are sexually dimorphic, altricial, and reach sexual maturity at 90 days after hatching [13]. In this species, pair bonding can be easily determined as beak fencing and nest construction [13]. Zebra finches have been extensively studied and are easily kept in captivity, characteristics that make them ideal subjects to study hormone disruption. Therefore, this species could be considered to study the effects of PCB exposures on passerine birds at doses lower than the concentrations assumed to cause negative effects in 
A.L. Hoogesteijn et al.

the wild [8]. This study was designed to evaluate whether oral pulse-exposure of an altricial species to a low dose of an environmentally relevant PCB mixture (Aroclor 1248) may be associated with modifications of reproductive performance and success, other breeding parameters (i.e., the number of clutches laid per breeding cycle, the number of nests the pairs constructed, and the incubation time per pair), or a combination of these, compatible with endocrine disruption.

\section{MATERIALS AND METHODS}

Healthy and fertile zebra finches from T. J. DeVoogd's (Ithaca, NY, USA) breeding colony were housed in an indoor avian viral isolation unit. Selected birds had previously laid at least one fertile clutch of eggs in breeding cages. Each cage (45.7 $\times 35.5 \times 43.1 \mathrm{~cm})$ contained two birds, one watering bottle, two wooden perches, one feeder bowl, and one bowl with ground oyster shell and cuttlebone (Agway, Ithaca, NY, USA) as a mineral source. A commercial diet (Kaytee Forti-Diet Finch Food, Kaytee Products, Chilton, WI, USA) was supplied ad libitum. Treatment and care of zebra finches were conducted in accordance with regulations set forth by Cornell's Institutional Animal Care and Use Committee. Twice as many birds as regarded necessary for the trial were preselected. Males and females were separated during the acclimatization period for four weeks. Twenty-four females were administered $40 \mu \mathrm{g}$ of Aroclor 1248 (AccuStandard) dissolved in corn oil at a concentration of $100 \mu \mathrm{g} / \mathrm{ml}$. A $0.1-\mathrm{ml}(10 \mu \mathrm{g}$ of Aroclor 1248) aliquot of the dosing solution was administered with a 20gauge, 3.8-cm stainless steel feeding (gavage) tube (L \& M Bird Leg Bands, San Bernardino, CA, USA) every $5 \mathrm{~d}$, four times, over a 16-d period. Fourteen control birds were exposed to the same vehicle (pure corn oil only). Ten days after the last treatment, 7 control females and 11 exposed females were randomly selected and paired with their previous mates. Spare birds were removed from the room. Cages had similar cage furniture as described above, plus two choices of nests, a plywood nest box and a wicker basket. Once the birds selected a nest, the unused nest was removed. Burlap strands $(8 \mathrm{~cm}$ long) were supplied as nesting material. Incandescent lights were on from 0630 to $1830 \mathrm{~h}$, and room temperature and humidity were $28^{\circ} \mathrm{C}$ and $65 \%$, respectively. Birds were observed daily for $2 \mathrm{~h}$ beginning $2 \mathrm{~h}$ after the lights were turned on. Nest boxes were checked daily for the presence of nest, eggs, and young. The laying date of individual eggs was recorded, and position in the laying sequence of individual eggs was marked on each eggshell with a nontoxic marker. Nest boxes were checked daily for egg hatching and number of surviving chicks and date of fledging were documented. Reproductive performance was measured by counting the number of nests built, number of clutches (a clutch was defined as a sequence of eggs with no more than $4 \mathrm{~d}$ passing between the laying of successive eggs), number of eggs laid, incubation length, hatching success (number of eggs hatched), and fledging success (number of young per pair to reach $40 \mathrm{~d}$ of age). Unhatched eggs were removed after $25 \mathrm{~d}$. Zebra finch eggs were taken at random from nests containing five or more eggs (maximum of two eggs withdrawn per nest). Ten control and 10 exposed eggs were then frozen at $-70^{\circ} \mathrm{C}$ and stored until chemical analysis. Whole eggs were analyzed for congenerspecific analysis [14] at the Public Health Analytical Laboratory, School of Public Health, State University of New York at Albany (Rensselaer, NY, USA), with detection limit $\geq 0.01$ $\mathrm{ng} / \mathrm{g}$ for defined PCB congeners. Results were reported on wet-

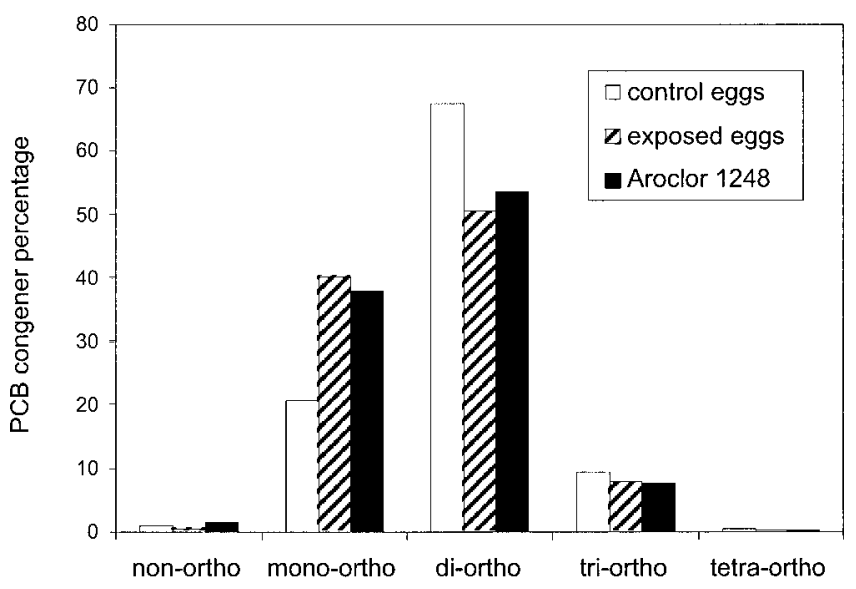

Fig. 1. ortho-Congener distribution (expressed in percentage) in eggs of control (total polychlorinated biphenyls $[\mathrm{PCBs}]=38.3 \mathrm{ng} / \mathrm{g}$ wet wt) and exposed female zebra finches (total PCBs $=196.9 \mathrm{ng} / \mathrm{g}$ wet wt), and in Aroclor 1248 used in this assay.

weight bases. The equality of two population medians and the corresponding point estimate were tested with the Mann-Whitney test with Minitab software (State College, PA, USA). When all observations of the control group were identical (i.e., number of dead hatchlings/clutch), the null hypothesis of median equal to zero versus the alternative (greater than zero) was conducted on experimental data with the Wilcoxon's sign test for the median. Results were considered significant at $p$ $<0.05$.

\section{RESULTS}

Within each sex, adult birds in each treatment group were comparable in age (one to two and one-half years), size (tarsus length), and body mass ( $p>0.05$; one-way analysis of variance). No damaged eggs were observed in active nests. Dead chicks were not analyzed. Twenty-one congeners were identified in sampled eggs. Figure 1 summarizes the Aroclor 1248 PCB congener residue content (expressed as percentages with defined chlorine distributions) in eggs, as well as the congener distribution of the used Aroclor 1248. At least nine congeners were found only in exposed eggs. Females treated with Aroclor 1248 had a fivefold increase in the total PCB content of their eggs (196.95 ng/g vs $38.32 \mathrm{ng} / \mathrm{g}$ ). Given that both groups received the same diet, differences could not be attributed to the diet. All control females laid one or two clutches of eggs. The control breeding pairs were highly synchronous (Table 1), requiring approximately seven weeks from the time re-pairing occurred to the time chicks started to shell seeds by themselves. In contrast, PCB-exposed females showed extended variability in the number of clutches, nests, and incubation time per pair (Table 2), displaying asynchrony and extended breeding cycle length. For instance, the number of eggs per pair varied between 1 and 23 for exposed birds (i.e., 23-fold variation), but varied less than twofold for controls. Some PCB-exposed pairs completely failed to hatch a clutch and renested constantly. These renesting attempts were not followed to completion. One exposed pair started five clutches. The median number of clutches laid per breeding cycle per pair, the median number of nests per pair, and the median incubation time per pair were significantly greater in exposed females than in controls $(p<$ 0.05). Median incubation time per clutch tended to be more protracted in exposed females $(p=0.07)$. The median number of eggs per clutch, median number of eggs per pair, median 
Table 1. Reproductive parameters of female control zebra finches (Taeniopygia guttata) administered with $40 \mu \mathrm{g}$ of corn oil orally

\begin{tabular}{lrrrrrrr}
\hline & \multicolumn{7}{c}{ Pair } \\
\cline { 2 - 7 } No. & 1 & 2 & 3 & 4 & 5 & 6 & 7 \\
\hline Clutches & 1 & 1 & 2 & 2 & 2 & 1 & 2 \\
Nests & 1 & 1 & 2 & 2 & 2 & 1 & 2 \\
Nests/clutch & 1 & 1 & 1 & 1 & 1 & 1 & 1 \\
Incubation & 0 & 13 & 12, & 25, & 14, & 15 & 17, \\
$\quad$ days/clutch & & & 14 & 25 & 25 & & 17 \\
Total eggs & 13 & 5 & 12 & 15 & 19 & 6 & 8 \\
Eggs/clutch & 13 & 5 & 6, & 5, & 4, & 6 & 4, \\
& & & 6 & 10 & 15 & & 4 \\
Chicks hatched & 0 & 4 & 12 & 0 & 4 & 3 & 6 \\
Chicks/clutch & 0 & 4 & 6, & 0 & 4, & 3 & 3, \\
& & & 6 & & 0 & & 3 \\
Fledglings & 0 & 4 & 12 & 0 & 4 & 3 & 6 \\
Fledglings/clutch & 0 & 4 & 6, & 0 & 4, & 3 & 3, \\
& & & 6 & & 0 & & 3 \\
Dead hatchlings/ & 0 & 0 & 0, & 0 & 0, & 0 & 0, \\
$\quad$ clutch & & & 0 & & 0 & & 0 \\
\hline
\end{tabular}

number of hatchlings per clutch, and median number of fledglings per clutch were not statistically significantly different between groups. Many chicks of exposed hens died after pipping. The median hatchling mortality percent per pair was greater in exposed birds ( $p=0.03$; Table 3). Causes of death, as defined by a pathologist, were inanition, hypothermia, or both.

\section{DISCUSSION}

The observed modification of female reproductive behavior after exposure to Aroclor 1248 supports the hypothesis that PCBs disrupt hormonal regulation. Findings should be con- sidered with caution. Results could not distinguish whether PCBs directly influence sexual functions or exert antihormone action(s). Laboratory data do not necessarily represent field situations; they rather reflect the minimum to be expected in the wild. For example, timing and duration of avian breeding cycles may be altered by field factors (i.e., climate and food availability in sufficient quantity and quality to feed the young), which, especially in temperate zones, may affect migrating birds. Possible mechanism(s) of action and models that facilitate their monitoring in the environment are here reviewed.

Congener content defines PCB toxicity $[1,5,15]$. One mechanism by which Aroclor 1248 disrupts hormonal regulation involves coplanar congeners, known to activate the aryl hydrocarbon receptor $[16,17]$. However, such a mechanism is unlikely to have played a relevant role in this study because coplanar congeners represent less than $2 \%$ of Aroclor 1248 mixtures. In contrast, the investigated compound contained di-, tri-, tetra-, and penta-ortho congeners at levels ranging between 21 and 55\% (Fig. 1). ortho-Substituted congeners generate different effects on exposed tissues. Many of them induce hepatic microsomal cytochrome $\mathrm{P} 450$ isozymes. In rats, mono- and di-ortho congeners tend to promote the synthesis of phenobarbital- and 3-methylcholanthrene-inducible forms of cytochrome P450 [15]. ortho-Substituted PCBs also affect the thyroid gland $[5,7,18]$. Birds exposed to ortho-substituted PCBs may develop hyperthyroidism (i.e., hyperactivity, decreased incubation attentiveness, and decreased brooding activity [19]), a syndrome associated with reduced body weight. While thyroid activity was not measured in this study, exposed birds did not lose body weight or express any behavior compensatory for weight loss (i.e., additional time devoted to feed-

Table 2. Reproductive parameters of female zebra finches (Taeniopygia guttata) orally exposed to $40 \mu \mathrm{g}$ of Aroclor 1248

\begin{tabular}{|c|c|c|c|c|c|c|c|c|c|c|c|}
\hline \multirow[b]{2}{*}{ No. } & \multicolumn{11}{|c|}{ Pair } \\
\hline & 1 & 2 & 3 & 4 & 5 & 6 & 7 & 8 & 9 & 10 & 11 \\
\hline Clutches & 2 & 2 & 3 & 3 & 4 & 3 & 1 & 3 & 3 & 1 & 5 \\
\hline Nests & 2 & 2 & 3 & 7 & 5 & 4 & 5 & 3 & 3 & 3 & 5 \\
\hline Nest/clutch & 1 & 1 & 1 & 2.3 & 1.2 & 1.3 & 5 & 1 & 1 & 3 & 1 \\
\hline Incubation days/clutch & $\begin{array}{l}17 \\
16\end{array}$ & $\begin{array}{l}15 \\
25\end{array}$ & $\begin{array}{l}14, \\
11, \\
25\end{array}$ & $\begin{array}{l}14, \\
16, \\
16\end{array}$ & $\begin{array}{l}25 \\
25 \\
25 \\
25\end{array}$ & $\begin{array}{l}25 \\
25 \\
25\end{array}$ & 25 & $\begin{array}{l}25 \\
17 \\
25\end{array}$ & $\begin{array}{l}25 \\
25 \\
25\end{array}$ & 25 & $\begin{array}{l}25, \\
15, \\
25, \\
19, \\
16\end{array}$ \\
\hline Total eggs & 13 & 22 & 18 & 23 & 24 & 22 & 6 & 13 & 1 & 2 & 23 \\
\hline Eggs/clutch & $\begin{array}{l}7 \\
6\end{array}$ & $\begin{array}{r}4 \\
18\end{array}$ & $\begin{array}{l}6 \\
8 \\
4\end{array}$ & $\begin{array}{c}6 \\
6, \\
11\end{array}$ & $\begin{array}{c}4 \\
10 \\
6 \\
4\end{array}$ & $\begin{array}{l}4, \\
9, \\
9\end{array}$ & 6 & $\begin{array}{l}1, \\
3, \\
9\end{array}$ & $\begin{array}{l}1, \\
0, \\
0\end{array}$ & 2 & $\begin{array}{l}4, \\
5, \\
6, \\
2, \\
6\end{array}$ \\
\hline Chicks hatched & 7 & 4 & 5 & 13 & 0 & 0 & 0 & 0 & 0 & 0 & 9 \\
\hline Chicks/clutch & $\begin{array}{l}4, \\
3\end{array}$ & $\begin{array}{l}4, \\
0\end{array}$ & $\begin{array}{l}4, \\
1, \\
0\end{array}$ & $\begin{array}{l}5, \\
1, \\
7\end{array}$ & $\begin{array}{l}0, \\
0, \\
0, \\
0\end{array}$ & $\begin{array}{l}0, \\
0, \\
0\end{array}$ & 0 & $\begin{array}{l}0, \\
3, \\
0\end{array}$ & $\begin{array}{l}0, \\
0, \\
0\end{array}$ & 0 & $\begin{array}{l}0, \\
4, \\
0, \\
2, \\
3\end{array}$ \\
\hline Fledglings & 3 & 4 & 2 & 10 & 0 & 0 & 0 & 3 & 0 & 0 & 7 \\
\hline Fledglings/clutch & $\begin{array}{l}2, \\
1\end{array}$ & $\begin{array}{l}4, \\
0\end{array}$ & $\begin{array}{l}2, \\
0, \\
0\end{array}$ & $\begin{array}{l}5, \\
1, \\
4\end{array}$ & 0 & $\begin{array}{l}0, \\
0, \\
0\end{array}$ & 0 & $\begin{array}{l}0, \\
3, \\
0\end{array}$ & $\begin{array}{l}0, \\
0, \\
0\end{array}$ & 0 & $\begin{array}{l}0, \\
4, \\
0, \\
0, \\
3\end{array}$ \\
\hline Dead hatchlings/clutch & $\begin{array}{l}2, \\
1\end{array}$ & $\begin{array}{l}0, \\
0\end{array}$ & $\begin{array}{l}2, \\
1, \\
0\end{array}$ & $\begin{array}{l}0, \\
0, \\
3\end{array}$ & $\begin{array}{l}0 \\
0, \\
0\end{array}$ & $\begin{array}{l}0, \\
0, \\
0\end{array}$ & $\begin{array}{l}0 \\
0, \\
0\end{array}$ & $\begin{array}{l}0, \\
1, \\
3\end{array}$ & 0 & 0 & 0 , \\
\hline
\end{tabular}


Table 3. Statistical analysis of reproductive parameters in female zebra finches (Taeniopygia guttata) nonexposed and orally exposed to Aroclor $1248^{\mathrm{a}}$

\begin{tabular}{lcc}
\hline & Control & Aroclor 1248 \\
\hline Total breeding pairs & 7 & 11 \\
Median number clutches laid/ $\quad$ Value b & & \\
$\quad$ breeding cycle (seven weeks)/pair & $2(1,2)$ & $3(0,5)$ \\
Median number of nests/pair & $2(1,2)$ & $3(2,7)$ \\
Median incubation time/pair & $15(0,25)$ & $22.3(0,25)$ \\
Median incubation time/clutch & $15(0,25)$ & $17(11,25)$ \\
Median number of eggs/clutch & $6.0(4,15)$ & $5.5(0,18)$ \\
Median number of eggs/pair & $12(5,19)$ & $0.04(1,24)$ \\
Median number of hatchlings/clutch & $3(0,6)$ & 0.01 \\
Median number of fledglings/clutch & $3(0,6)$ & 0.07 \\
Median hatchling mortality percent/pair & 0 & 0.15 \\
\hline
\end{tabular}

a Numbers in parentheses denote minimum and maximum values.

b Mann-Whitney test. Considered statistically significant if $p \leq 0.05$.

ing, or increased consumption of seeds). Instead, the observed high mortality of chicks hatched from PCB-exposed females was caused by inanition, hypothermia, or both-factors normally related to maternal care. Because newly hatched chicks have limited capabilities to thermoregulate, lack of incubation could lead to death by hypothermia. It is also improbable that chicks died due to the mobilization of PCBs from the yolk, because egg residue levels were at concentrations one to two orders of magnitude below levels reported to cause developmental abnormalities (for example, [20,26-34]). A likely mechanism of action that may explain at least some of the effects induced by Aroclor 1248 in this study is a nonspecific morbidity or increased stress, which results in cessation of egg laying, interruption of incubation, or reduced care of chicks, events reported in birds contaminated with petroleum [11].

Endocrine disruption is expressed in two types of reproductive endpoints: those associated with physiologic events, and those related to behavior. Most common endpoints evaluated in avian toxicology relate to physiologic events. They are number of eggs per nest, hatching success, number of nestlings per nest, number of fledglings per nest, and fledging success. Changes in these parameters are generally observed when the investigated chemical is present at high concentrations [20]. In contrast, this study investigated reproductive parameters in zebra finch hens exposed to low PCB doses, which revealed multiple changes in reproductive variables but not typical signs of toxicity (such as tremors, paralysis, anorexia, nephromegaly, or reduced heart or spleen size). No acute or protracted zebra finch hen mortality was observed, which is compatible with the low PCB dose used. Aroclor 1248 did not seem to alter physiologic reproductive events (e.g., egg-laying capacity) but rather affected reproductive parameters related with parental attentiveness, such as nesting and incubating behavior [8]. Asynchrony and lengthening of the breeding cycle induced by persistent organic pollutants present in the trophic food chain may have considerable ecological implications in the reproduction of altricial birds. Their breeding chances may be reduced because the successful production of offspring is not only expressed as gametogenesis, fertilization, and hatching, but also as parental posthatch care for their chicks.

Most prior research relating PCB level to reproduction in birds has examined pisciporous or insectivorous species. Such species readily accumulate high levels of PCBs because they are high on the food chain [5]. If even low PCB concentrations (such as those used in this study) may be associated with reproductive dysfunction, many more PCB-mediated harmful effects could be predicted for birds feeding on higher components of the food chain (i.e., piscivorous or insectivorous avian species). In addition, the current data indicate that such birds may be at risk of impairments in reproductive behaviors even in habitats not now seen as severely contaminated. That potential risk may be greater for species that only build a single nest, because such species may lose their only chance to assure survival and bird recruitment in the next generation. Endpoints traditionally measured to assess PCB effects may result in false-negative results. To prevent erroneous results, we suggest evaluating neuroendocrinally regulated endpoints (i.e., number of clutches per breeding cycle, number of nests per clutch, nest quality, incubation time, and cause of death in hatchlings). The observed alterations of reproductive behavior may represent early signs of low-dose PCB toxicity.

Avian species have been extensively used as environmental sentinels. Traditionally, the U.S. Environmental Protection Agency and the Organization for Economic Cooperation and Development have required avian reproductive toxicity tests for pesticide registration. At present, these tests are conducted with bobwhites, quail, Japanese quail, and mallard ducks [21]. The high cost and length of testing time ( $>20$ weeks) associated with these species preclude the evaluation of endocrine disruption. According to ornithological classifications that consider offspring maturity at hatching, the species recommended by the U.S. Environmental Protection Agency and the Organization for Economic Cooperation and Development are precocial [22]. The neuroendocrine behavioral factors of these species are, at least in part, not being evaluated. The tests on these species do not monitor nest construction quality, incubation time, interval between egg laying, number of eggs per clutch, maternal and paternal care, thermoregulatory care of the hatched chick, or feeding and food-begging behavior. Zebra finches and other passerine species have been recommended for testing endocrine disruption [23]. Given their shorter breeding cycle (more than seven weeks), zebra finches might prove useful for detecting endocrine-disrupting chemicals. Another advantage of altricial over precocial species relates to the critical period of chemically induced behavioral differentiation. Although masculine sex in quail cannot be reversed by estrogen injections after $12 \mathrm{~d}$ of incubation, zebra finches are capable of exhibiting sex reversal even one week after hatching [24]. Because of their long window for endocrine-disruptive interference, zebra finches may be better suited than precocial 
species for the evaluation of hormone-disrupting chemicals and behavioral teratology.

We conclude that Aroclor 1248 at low doses impairs reproduction in zebra finches. Altricial birds exposed to endocrine-disruptive chemicals (PCBs) may show reproductive behavioral changes before they display somatic and physiologic changes. Given their reproductive features, zebra finches are recommended as an experimental species to monitor environmental pollutants likely to induce endocrine disruption.

Acknowledgement-Funding for this research was provided by the Teresa Heinz Scholars for Environmental Research, and National Science Foundation grant IBN90963 to T.J. DeVoogd. We are grateful to Ariel Rivas for the production of the manuscript.

\section{REFERENCES}

1. Safe S. 1990. Polychlorinated biphenyls (PCBs), dibenzo-p-dioxins, dibenzofurans (PCDFs), and related compounds: Environmental and mechanistic considerations which support the development of toxic equivalent factors (TEFs). Crit Rev Toxicol 21: 51-88.

2. Safe S, Hutzinger O. 1987. Polychlorinated Biphenyls (PCBs): Mammalian and Environmental Toxicology. Springer-Verlag, Berlin, Germany.

3. Berger DF, Lombardo JP, Jeffers PM, Hunt AE, Bush B, Casey A, Quimby F. 2001. Hyperactivity and impulsiveness in rats fed diets supplemented with either Aroclor 1248 or PCB-contaminated St. Lawrence river fish. Behav Brain Res 126:1-11.

4. Tyler CR, Jobling S, Sumpter JP. 1998. Endocrine disruption in wildlife: A critical review of the evidence. Crit Rev Toxicol 28: 319-361.

5. Hoffman DJ, Rice CP, Kubiak T. 1996. PCBs and dioxins in birds. In Beyer W, Heinz G, Redmon-Norwood A, eds, Environmental Contaminants in Wildlife, 1st ed. CRC Lewis, Boca Raton, FL, USA, pp 165-208.

6. Hansen LG. 1999. The Ortho Side of PCBs Occurrence and Disposition. Academic, Boston, MA, USA.

7. Schulz DE, Petrick G, Duinker JC. 1989. Complete characterization of polychlorinated biphenyl congeners in commercial Aroclor and Clophen mixtures by multidimensional gas chromatography electron capture detection. Environ Sci Technol 23:852859.

8. Barron MG, Galbraith H, Beltman D. 1995. Comparative reproductive and developmental toxicology of PCBs in birds. Comp Biochem Physiol C Pharmacol Toxicol Endocrinol 112:1-14.

9. Becker PH, Schuhmann S, Koepff C. 1993. Hatching failure in common terns (Sterna hirundo) in relation to environmental chemicals. Environ Pollut 79:207-213.

10. Fox GA, Gilman AP, Peakall DB, Anderka FW. 1978. Behavioral abnormalities of nesting Lake Ontario herring gulls. J Wildl Manag 42:477.
11. Fry DM. 1995. Reproductive effects in birds exposed to pesticides and industrial chemicals. Environ Health Perspect 103:165-171.

12. Peakall DB. 1998. Animal Biomarkers as Pollution Indicators. Chapman \& Hall, London, UK.

13. Zann RA. 1996. The Zebra Finch: A Synthesis of Field and Laboratory Studies. Oxford University Press, Oxford, UK.

14. DeCaprio AP, Tarbell AM, Bott A, Wagemaker DL, Williams RL, O'Hehir CM. 2000. Routine analysis of 101 polychlorinated biphenyl congeners in human serum by parallel dual-column gas chromatography with electron capture detection. J Anal Toxicol 24:403-420.

15. Parkinson A, Safe S. 1987. Mammalian biologic and toxic effects of PCBs. In Safe S, Hutzinger O, eds, Polychlorinated Biphenyls (PCBs): Mammalian and Environmental Toxicology, 1st ed. Springer-Verlag, Berlin, Germany, p 152.

16. Andric SA, Kostic TS, Stojilkovic SS, Kovacevic RZ. 2000. Inhibition of rat testicular androgenesis by a polychlorinated biphenyl mixture Aroclor 1248. Biol Reprod 62:1882-1888.

17. Davis D, Safe S. 1989. Dose-response immunotoxicities of commercial polychlorinated biphenyls (PCBs) and their interaction with 2,3,7,8-tetrachlorodibenzo-p-dioxin. Toxicol Lett 48:35-43.

18. Jefferies DJ. 1975. The role of the thyroid in the production of sublethal effects by organochlorine insecticides and polychlorinated byphenyls. In Moriarty F, ed, Organochlorine Insecticides, 1st ed. Academic, London, UK, p 131.

19. Peakall DB, Peakall ML. 1973. Effect of a polychlorinated biphenyl on the reproduction of artificially and naturally incubated dove eggs. J Appl Ecol 10:103.

20. Fent K. 1995. Endocrinically active substances in the environment: State of the art. Proceedings, Endocrinically Active Chemicals in the Environment, Berlin, Germany, March 9-10, 1995, p 151.

21. Benson WH, Van Der Kraak G, Tyler C, Brugger KE, Daston G, Fry DM, Gimeno S, Hunger F, Kolossa M, Länge R, Matthiessen P. 1997. Strategies and approaches to in vivo screening and testing in identifying the hazards of endocrine modulating chemicals to wildlife. Proceedings, SETAC-Europe/OECD/EC Expert Workshop on Endocrine Modulators and Wildlife: Assessment and Testing, Veldhoven, The Netherlands, April 10-13, 1997, p 126.

22. Ehrlich PR, Dobkin DS, Wheye D. 1988. The Birder's Handbook A Field Guide to the Natural History of North American Birds. Simon and Schuster, New York, NY, USA.

23. Ankley G, Mihaich E, Stahl R, Tillitt D, Colborn T, McMaster S, Miller J, Bantle P, Campbell N, Denslow R, Dickerson R, Folmar L, Fry M, Giesy J, Gray LE, Guiney P, Hutchinson T, Kennedy S, Kramer V, Leblanc G, Mayes M, Nimrod A, Patino R, Peterson R, Purdy R, Ringer R, Thomas P, Touart L, Van DKG, Zacharewski T. 1998. Overview of a workshop on screening methods for detecting potential (anti-) estrogenic/androgenic chemicals in wildlife (Kansas City, Missouri, USA, March 1997). Environ Toxicol Chem 17:68-87.

24. Adkins-Reagan E, Mansukhani V, Seiwert C, Thompson R. 1994. Sexual differentiation of brain and behavior in zebra finch-Critical periods for effects of early estrogen-treatment. $J$ Neurobiol $25: 865-877$. 